\title{
Preparation of Fibrillated Cellulose from Kenaf Bast Fiber Using High Speed Homogenizer without Pressure
}

\author{
Nurul Husna Osman, Rosazley Ramly, Wan Haslinda Wan Ahmad, Ainun Zuriyati Mohamed @ \\ Asa'ari
}

\begin{abstract}
The aim of the study is to characterize the fibrillated cellulose (FC), which has been extracted from kenaf bast fiber using high speed homogenizer $(\mathrm{HSH})$. The $\mathrm{FC}$ was prepared by applying 10,000, 15,000 and 20,000 rpm of homogenization process for 10, 15 and 20 mins. Morphological observation via Field Emission Scanning Electron Microscope (FESEM) was carried out in order to observe the sur-face morphology of FC while Fourier Transform Infrared (FTIR) spectroscopy was performed to determine the changing of functional groups. Thermogravimetric Analysis (TGA) was done for thermal decomposition of FC. Results showed that the diameter of the FC from kenaf bast was determined below $100 \mathrm{~nm}$. The Fourier Transform Infrared (FTIR) spectroscopy showed that lignin and hemicellulose were almost completely removed during the bleaching process at peak 1,737 cm-1. In addition, thermogravimetric analysis (TGA) displayed $272^{\circ} \mathrm{C}$ as the highest temperature for thermal stability of FC. In conclusion, by controlling the speed during homogenization process, $F C$ was successfully obtained. Such FC can be applied as beneficial main ingredients in papermaking and packaging industry, which dedicat-ed to mechanical strength properties.
\end{abstract}

Index Terms: Fibrillated cellulose; Kenaf bast fiber; High speed homogenizer

\section{INTRODUCTION}

Kenaf (Hibiscus cannabinus L) is a non-wood lignocellulose material because it consists of cellulose, hemicellulose and lignin. Kenaf is originated from Africa and can be found in some parts of the world especially in African countries such as Tanzania, Kenya and Sudan [1]. In Malaysia, kenaf has been planted in year 2010 at 2,000 hectares area including Kelantan, Terengganu and Pahang. The growth and potential of kenaf crops in the country is because of the high demand from China, which is about 200 tonnes per month. The chemical composition of kenaf bast is around $63.5 \%$ cellulose, $17.6 \%$ hemicellulose and $12.7 \%$ lignin [2]. Meanwhile, kenaf core is around $46.1 \%$ cellulose,

Revised Manuscript Received on July 05, 2019.

Nurul Husna Osman, Department of Physics, Faculty of Science and Mathematics, Universiti Pendidikan Sultan Idris, 35900 Tanjong Malim, Perak, Malaysia

Dr. Rosazley Ramly, Department of Physics, Faculty of Science and Mathematics, Universiti Pendidikan Sultan Idris, 35900 Tanjong Malim, Perak, Malaysia.Corresponding author.Email: rosazley@fsmt.upsi.edu.my

Dr. Wan Haslinda Wan Ahmad, Department of Chemistry, Faculty of Science and Mathematics, Universiti Pendidikan Sultan Idris, 35900 Tanjong Malim, Perak, Malaysia.

Dr. Ainun Zuriyati Mohamed @ Asa'ari, Institute of Tropical Forestry and Forest Products (INTROP), Universiti Putra Malaysia, 43400 UPM Ser-dang, Selangor, Malaysia. Corresponding author. Email: ainunzuriyati@upm.edu.my
$29.7 \%$ hemicellulose and $22.1 \%$ lignin [3]. An average length of fiber is $2740 \mu \mathrm{m}$, which is higher than wood (840 $\mu \mathrm{m})$ and an average diameter at $20 \mu \mathrm{m}$ [4]. There are various new applications for kenaf such as paper production. Natural fibers such as kenaf have many benefits over manufactured fibers such as glass and carbon because of its low cost, low density, high specific strength properties and carbon dioxide seclusion [5]. There is an increasing attraction in the application of kenaf fibers because kenaf has great mechanical properties and can grow fast within 4-5 months [6].

Cellulose is one of the most plentiful natural polymers on the earth. It has many special properties in terms of biocompatibility, degradability and sustainability [8-9]. Cellulose is deliberated as an almost unlimited source of raw material in the high demand for environmentally friendly and biocompatible products. Nano-size cellulose also known as a nano-fiber has attracted a good deal of consideration during the past few years. Nanocellulose isolated from plant, agriculture or forest can be categorized in two main subcategories, which are nanofibrillated cellulose (NFC) and nanocrystalline cellulose (NCC) based on cellulosic source and the processing surroundings and have a diameter in between 3-10 nm [10-11] but, because of hydrolysis and separation of amorphous regions, lengths of NCC are in the range 100-200 nm [10], while NFC can be reach to microns long [12]. Current studies prefer NCC applications in the pharmaceutical industry as a tablet binder [13] or a bioimaging agent [14], assist by a high surface charge density [15-16]. The nanofibrillated cellulose (NFC) has various of characteristics such as a large surface-to-volume ratio, great mechanical properties and the capability to form very well porous mesh [17]. Therefore, the preparation and application of NFCs from renewable resources have achieved much attention during the past several years. In pre-vious study done by Jonoobi et al [7], the nanofibrillated cellulose was successfully produced from kenaf stem fibers by chemo-mechanical treatments which had diameters in the range of $15-25 \mathrm{~nm}$.

There are few ways to prepare NFC. It was reported that the combination of chemical and mechanical treatment could be sufficient to isolate kenaf fibers from bleached kenaf bast pulp. It can be conducted by applying chemical pre-treatment of kenaf bast pulp using $\mathrm{NaOH}-\mathrm{AQ}$ (anthraquinone) followed by three stages of bleaching process [2]. In

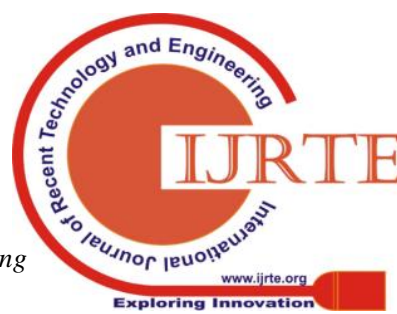


mechanical step, a bleached pulp was ground by Willey Mill and then soaked with distilled water as an earlier step to pass through high-pressure homogenization (HPH). One of the valuable things correlate to HPH is the clogging issue because of its confined orifice size. To overcome this issue, it is essential to diminish the size of fibers before fleeting through HPH. A research investigated that isolation of nanofibrillated cellulose (NFC) can be carried out from different cellulosic sources using mechanical, chemical or the mix of mechanical and chemical (chemo-mechanical) methods [18]. At the same time, the preparation of cellulose by grinding will reduce the thermal expansion properties [19] but the process will cutback the crystalline degree of NFC, disk maintenance and substitute. A research discovered that the combination of chemo-mechanical technique for extraction of NFC from oil palm empty fruit bunch fiber did not affect the surface morphology but it will reduce the size of cellulose within range of 5 to $10 \mathrm{~nm}$ [7].

To date, most studies that reporting on preparation of FC used mechanical process in terms of refining and homogenizing which applied pressure. Therefore, the study focused on the application of HSH without any pressure in order to isolate FC from kenaf bast. This is to determine any chances in obtaining NFC by excluding the pressure during the mechanical processes by con-trolling the speed and duration

\section{MATERIALS AND METHODOLOGY}

The kenaf bast fibers were purchased from the National Kenaf and Tabacco Board, Malaysia. The kenaf bast fibers were received in dried form at 1.0 to $1.5 \mathrm{~m}$ in length.

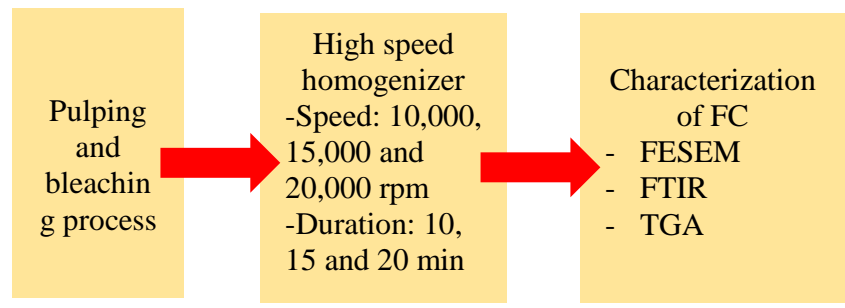

Fig. 1: Preparation of FC from kenaf bast fiber

The kenaf bast was cut to $2-3 \mathrm{~cm}$ in length. The kenaf bast fibers were pulped using soda-AQ pulping process and followed by bleaching process to remove non-cellulosic materials from kenaf bast fiber. The liquor to kenaf fiber ratio selected as $6: 1$ with the addition of $0.1 \%$ anthraquinone. The pulping was carried out at $170^{\circ} \mathrm{C}$ for 90 mins using a rotary digester (Weverk model, Sweden). A bleaching treatment was completed according to DEDED se-quence in order to remove any enduring lignin by using $3 \% \mathrm{ClO} 2,3 \%$ acetic acid represent for $\mathrm{D}$ and $1 \% \mathrm{NaOH}$ represent for $\mathrm{E}$. All overall bleaching treatment process was done at $70^{\circ} \mathrm{C}$ for $2 \mathrm{~h}$. Bleached fibers were finally obtained to be used in next process.

The FC of kenaf bast fiber was performed by passing the fibers at 10,000, 15,000 or 20,000 rpm of speed through high speed homogenization (QSonica model, USA). Three samples represented each homogenization speeds were prepared according to 10,15 or 20 mins period length of process. The optimal speed and time were then chosen throughout the study. Fig. 1 shows the process in preparing FC for kenaf bast fiber.

The surface morphology of FC was carried out using a Field Emission Scanning Electron Microscope (FESEM) model Hitachi SU 8020. The accelerating voltage used was $2.0 \mathrm{kV}$ at a working distance $8.5 \mathrm{~mm}$. The FCs were pasted onto a substrate covered with carbon tape and coated with a $3.5 \mathrm{~mm}$ layer of platinum to reduce charging effect during scanning process. The Fourier Transform Infrared (FTIR) spectroscopy Thermo Nicolet 6700 model was performed to study the changing of functional groups that may have been affected by the high-speed homogenization process. The spectra were recorded between 4,000 and $500 \mathrm{~cm}-1$ via 32 scans. Thermogravimetric Analysis (TGA) was done using a Shimadzu brand (model: TGA-50). An amount of $10 \mathrm{mg}$ of fibers was heated in a nitrogen atmosphere with heating rate of $10^{\circ} \mathrm{C} / \mathrm{min}$. The tem-perature was set between 20 and $450^{\circ} \mathrm{C}$.

\section{RESULTS AND DISCUSSIONS}

The development of the morphological structure of the fibers is important to express the fiber-matrix interaction. Table 1 shows the FESEM images of fibers which passed HSH with 10, $000 \mathrm{rpm}, 15,000 \mathrm{rpm}$ and 20, $000 \mathrm{rpm}$. The diameter of the fiber was measured using ImageJ software.

It was observed that the morphology of the fibers was strongly entangled in Table 1 (a), (b) and (c) shows that the fiber start to break into smaller size. The images displayed that there are more surface area are formed between the fibers. The diameters of the fibers after passing 10,000 rpm of HSH were found to be $35 \mathrm{~nm}$ for $10 \mathrm{~min}, 34 \mathrm{~nm}$ for $15 \mathrm{~min}$ and $30 \mathrm{~nm}$ for $20 \mathrm{~min}$.

There were lot of tiny fibrils was developed on the fiber surface as shown in Table 1 (d), (e) and (f) after the fiber passed through $15,000 \mathrm{rpm}$ of homogenization process. It was clearly showed that the cellulose fibers were almost completely broken down into fibrillated cellulose (FC) after high-speed homogenization. The diameter of kenaf bast fibrillated cellulose fiber produced was in the range of 30 to $35 \mathrm{~nm}$. Table $1(\mathrm{~g})$, (h) and (i) shows the surface morphology of the fibers after homogenization process with speed of $20,000 \mathrm{rpm}$ for 10,15 and $20 \mathrm{~min}$. The FESEM images clearly reveal that the fiber cell wall was totally broken and large surface area was discovered. There are more fibrils was formed after $20 \mathrm{~min}$ of homogenization. It can be concluded that, the higher the speed and time of homogenization, the higher the surface area was created. However, the diameters of the $\mathrm{FC}$ were between 25 to $30 \mathrm{~nm}$ respectively.

Table 1: FESEM images of fibers which passed HSH with 10, $000 \mathrm{rpm}, 15,000 \mathrm{rpm}$ and 
20, $000 \mathrm{rpm}$ for 10,15 and $20 \mathrm{~min}$.

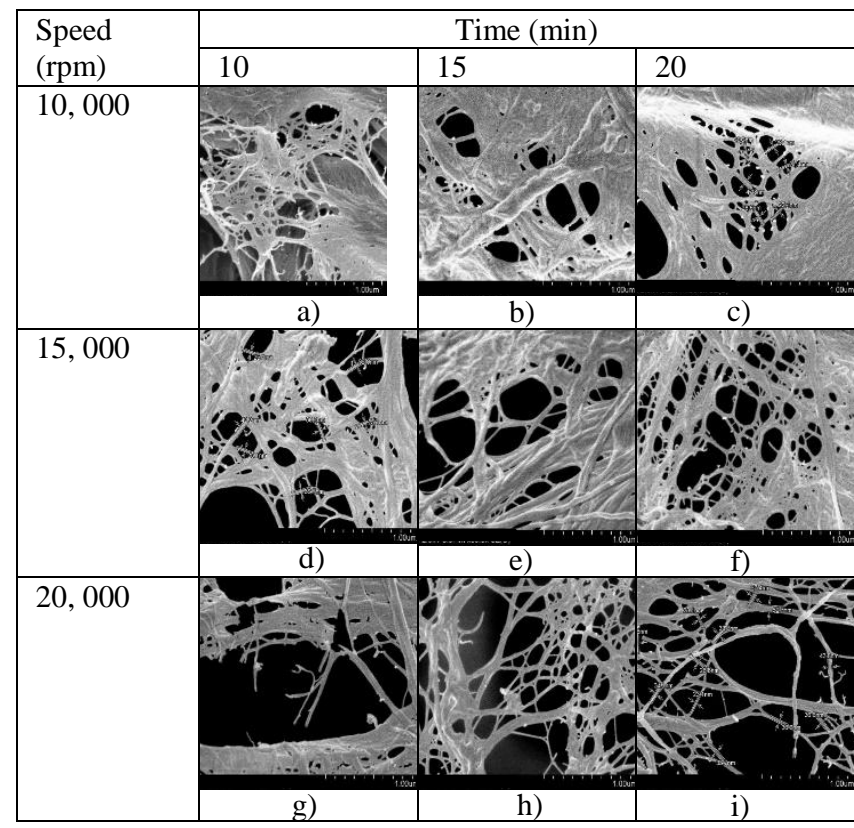

These results demonstrated that high speed of homogenizer was efficient to reduce the kenaf bast diameter to nanometer or micrometer size. From the images in Table 1, it can be summarized that the longer the duration of homogenization process therefore more surface area discovered and the diameter reduced into nano size. This finding are parallel to Jonoobi et al [2] which the isolation of nano-fibrillated cellulose from unbleached and bleached pulp had diame-ters between 10 to $90 \mathrm{~nm}$ using chemical and mechanical treatments.

The particle size test was done to analyze the size distribution by volume. Table 2 show the result of particle size test.

Table 2: Size distribution of fibrillated cellulose from kenaf bast fiber

$\begin{array}{llll} & \text { Size }(\mathrm{nm}) & \text { Volume }(\%) & \text { St. Dev }(\mathrm{nm}) \\ \text { Peak 1 } & 65.95 & 18.0 & 24.85 \\ \text { Peak 2 } & 546.3 & 62.5 & 117.3 \\ \text { Peak 3 } & 2367 & 0.2 & 357.6\end{array}$

There was only $18 \%$ of fiber are in the range of below 100 $\mathrm{nm}$. It can be considered that the fiber was not completely reach the nano-size because of duration of high-speed homogenization process.

Fig. 2 shows the FTIR spectra analysis of the FC prepared by high speed homogenization. The FC was most constituted of cellulose, hemicellulose and lignin and other substances after pulping and bleaching process. There was no new absorption peak that reveals for FC in the range 3700-3200 $\mathrm{cm}^{-1}$ for all spectra. The absorbance peaks displays in the range of $3400-3300 \mathrm{~cm}^{-1}$ area was referred to the stretching of the O-H group while the peaks between $2900-2800 \mathrm{~cm}^{-1}$ were assigned to the stretching of $\mathrm{C}-\mathrm{H}$ [20]. The peak placed in between $1800-1700 \mathrm{~cm}^{-1}$ was attributed to the $\mathrm{C}=\mathrm{O}$ stretching at the acetyl group in hemicellulose [21-22] or the ester linkage of carboxylic group in the Ferulic and p-coumeric acids of lignin and/or hemicellulose [23]. At the peak between $1380-1320 \mathrm{~cm}^{-1}$, there are bending vibration of $\mathrm{C}-\mathrm{H}$ and C-O groups of aromatic ring in polysaccharides [24]. Peak between $1737 \mathrm{~cm}^{-1}$ assigned to carbonyl group stretching vibration for acetyl and ester linkage present in hemicellulose [18]. These factors are characteristic of the cellulose that present in all fibers.
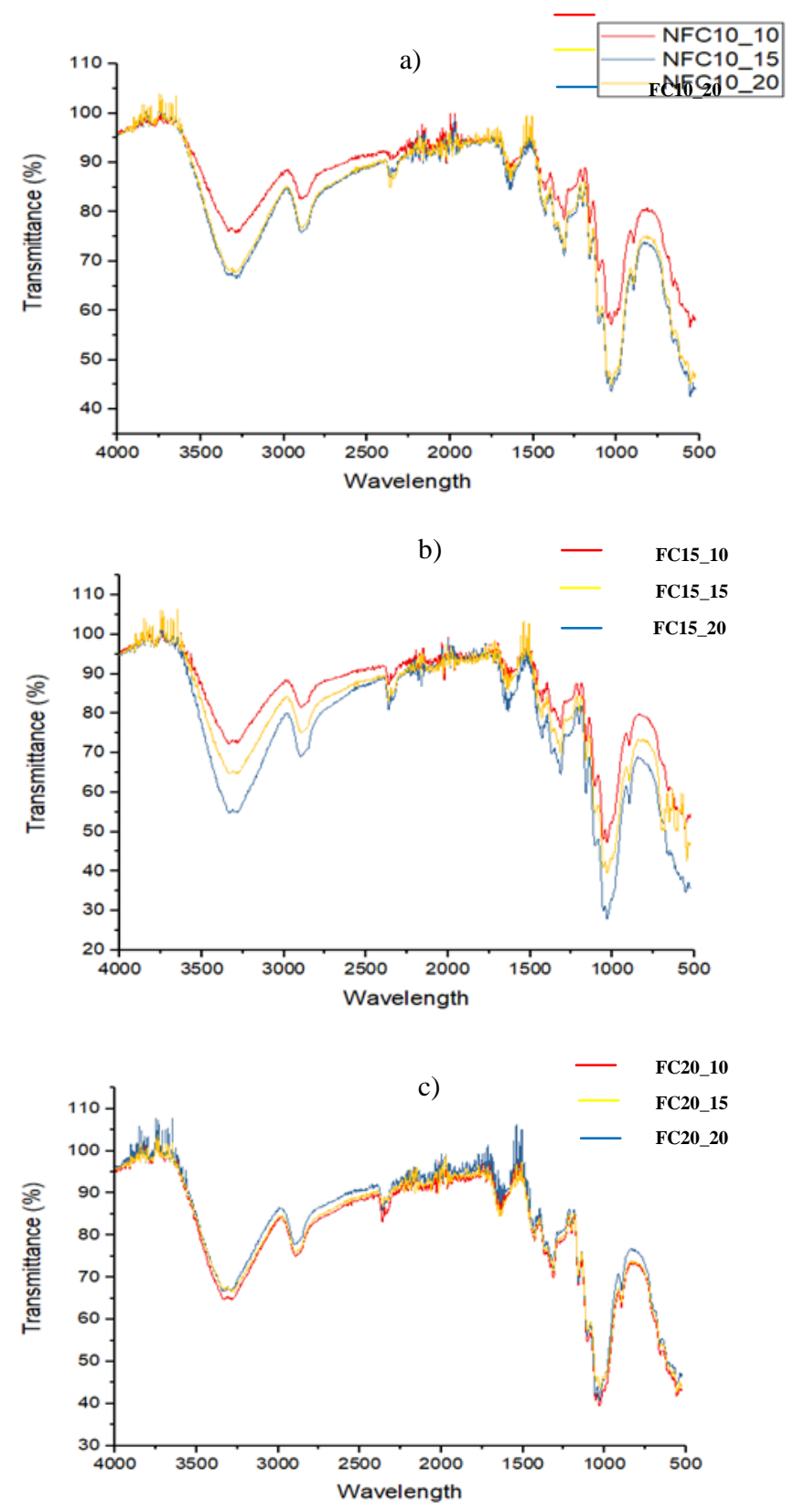

Fig. 2: FTIR (Fourier Transform Infrared) spectra analysis of kenaf bast fiber during high speed of homogenization: a) 10 $000 \mathrm{rpm}$, b) $15000 \mathrm{rpm}$ and c) $20000 \mathrm{rpm}$

TGA was performed to study the properties of the kenaf bast fiber for thermal stability. It is generally approved that the primary thermal decomposition of cellulosic materials takes place between 200 and $400^{\circ} \mathrm{C}$ [25]. The primary decomposition of the cellulosic components occurs mostly in the amorphous area [26]. Fig. 3 (a), (b) and (c) shows the thermogravimetric data equivalent to the kenaf bast fibers. 


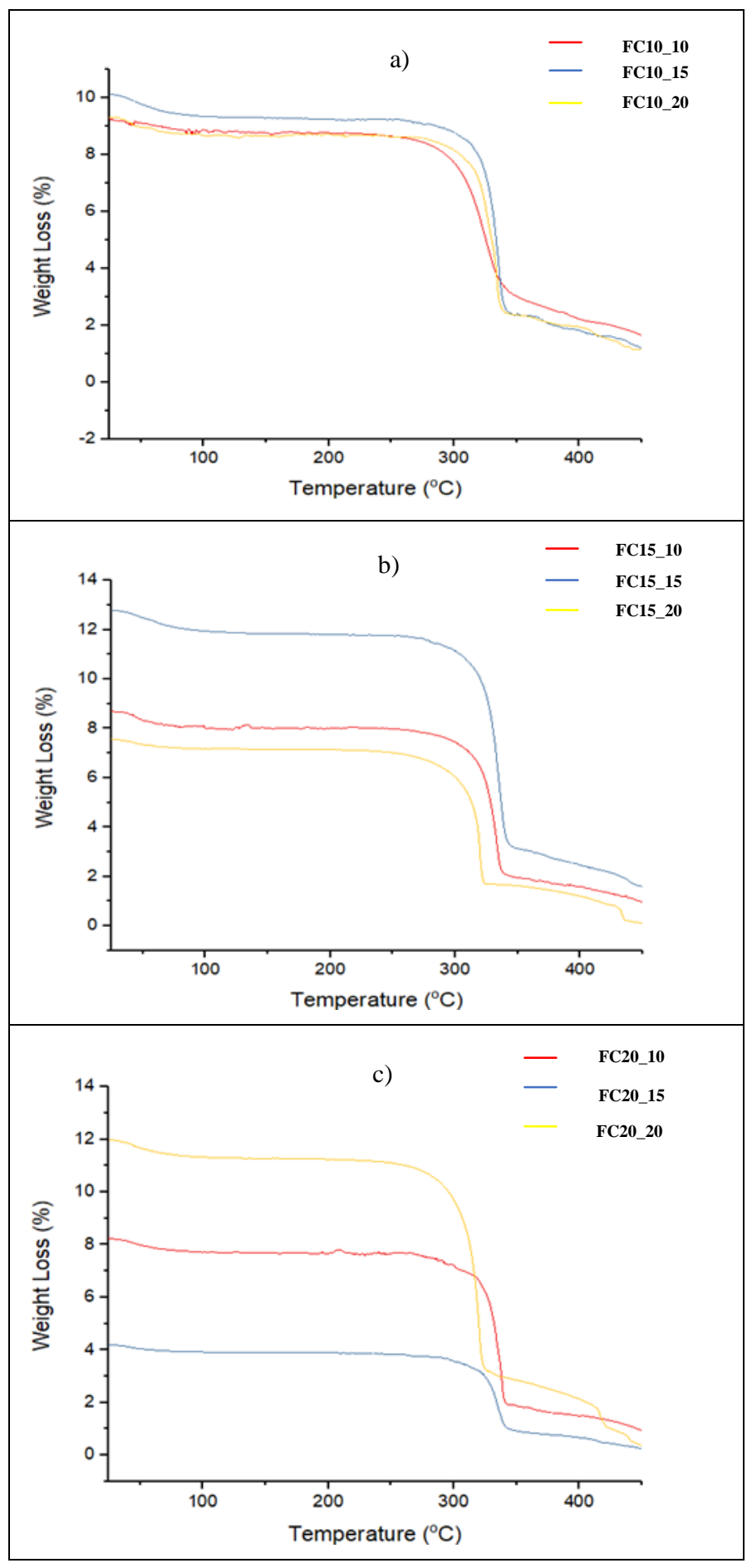

Fig. 3: TGA (Thermogravimetric Analysis) graph of kenaf bast fiber during high speed of homogenization: a) 10000 rpm, b) $15000 \mathrm{rpm}$ and c) $20000 \mathrm{rpm}$

The data in Fig. 3 displays an increasing thermal stability for the series of FC produced from homogenization process. The major degradation step (Tmax) was discovered for 240, 241 and 250 when passed 10,000 rpm of $\mathrm{HSH}$ for 10, 15 and $20 \mathrm{~min}$. After that, the major degradation step (Tmax) was found for 15,000 rpm of $\mathrm{HSH}$ at 10, 15 and $20 \mathrm{~min}$ were 251, 256 and 259. An amount of 20,000 rpm of HSH influenced the major degradation step (Tmax) that discovered 261, 271 and $300^{\circ} \mathrm{C}$ for 10,20 and $15 \mathrm{~min}$. The high thermal stability was obtained in FC20_15 fiber because of the speedy defibrillation of FC by the impact of the high speed homogenization process. Among all these results, FC20_15 showed an optimum result for thermogravimetric analysis.
FC20 15 represented such fiber that had passed 20, $000 \mathrm{rpm}$ of $\mathrm{HSH}$ for $15 \mathrm{~min}$.

\section{CONCLUSIONS}

In this study, fibrillated cellulose fibers were successfully isolated from kenaf bast fiber using high-speed homogenization with different speed and time of processes. FESEM studies showed that the longer the duration and high speed of homogenizer, more surface areas were created and the diameter of FC was reduced with-in range of 25 to $35 \mathrm{~nm}$ by using Image J analysis but the FC does not reach nano size after analyzed by particle size analyzer which reveal only $18 \%$ of fiber were formed into nanofibrillated cellulose (NFC). Futher study must be done by increasing the duration of high-speed homogenization process to get nano size of FC from kenaf bast fiber. FTIR analysis displayed the stretching of O-H at peak 3400-3300 cm-1 in all spectra which referred to the characteristics of the cellulose. TGA showed that the thermal stability increased when the speed of homogenizer increased. As conclusion, the high-speed homogenization process can be applied to produce fibrillated cellulose. It is also can be used as a potential equipment to produce nanofibrillated cellulose from kenaf fibers.

\section{ACKNOWLEDGEMENT}

This research has been carried out under Top Down Grant (code: 2016-0221-102-41) under Kementerian Pengajian Tinggi, Universiti Pendidikan Sultan Idris (UPSI) for the short-term grant (code: 2012-0068-102-01 and 2015-0047-102-01) and Ministry of Education Malaysia for the Programme Research Acculturation Collabrative Effort (RACE) grant (code: 2012-0148-102-62).

\section{REFERENCES}

1. J. Xu et al., "Genetic diversity and phylogenetic relationship of kenaf (Hibiscus cannabinus L.) accessions evaluated by SRAP and ISSR," Biochem. Syst. Ecol., vol. 49, pp. 94-100, 2013.

2. M. Jonoobi, J. Harun, A. Shakeri, M. Misra, and K. Oksmand, "Chemical composition, crystallinity, and thermal degradation of bleached and unbleached kenaf bast (Hibiscus cannabinus) pulp and nanofibers," BioResources, vol. 4, no. 2, pp. 626-639, 2009.Cho JH Chang SA, Kwon HS, Choi YH, KoSH, Moon SD, Yoo SJ, Song KH, Son HS, Kim HS, Lee WC, Cha BY, Son HY \& Yoon KH (2006), Long-term effect of the internet-based glucose monitoring system on HbA1c Reduction and glucose stability: a 30-month follow-up study for diabetes management with a ubiquitous medical care system. Diabetes Care 29, 2625-2631.

3. A. Ashori, "Chemical and Morphological Characteristics of Malaysian Cultivated Kenaf ( Hibiscus cannabinus ) Fiber," Polym. Plast. Technol. Eng., vol. 45, pp. 131-134, 2006.

4. R. W. Hurter, "Nonwood Plant Fiber Characteristics HurterConsult," HurterConsult, no. August, pp. 1-4, 2001.

5. A. K. Mohanty, M. Misra, and L. T. Drzal, "Sustainable Bio-Composites from renewable resources: Opportunities and challenges in the green materials world," J. Polym. Environ., vol. 10, no. 1-2, pp. 19-26, 2002.McMahon GT, Gomes HE, Hohne SH, Hu TM, Levine BA \& Conlin PR (2005), Web-based care management in patients with poorly controlled diabetes. Diabetes Care 28, 1624-1629.

6. Y. Li and Y.-W. Mai, "Interfacial Characteristics of Sisal Fiber and Polymeric Matrices,” J. Adhes., no. November 2014, pp. 527-554, 2006.

7. M. Jonoobi, J. Harun, P. M. Tahir, A. Shakeri, S. Saifulazry, and M. D. Makinejad, "Physicochemical characterization of pulp and nanofibers from kenaf stem," 
Mater. Lett., vol. 65, no. 7, pp. 1098-1100, 2011.

8. W. Chen, H. Yu, Y. Liu, P. Chen, M. Zhang, and Y. Hai, "Individualization of cellulose nanofibers from wood using high-intensity ultrasonication combined with chemical pretreatments," Carbohydr. Polym., vol. 83, no. 4, pp. 1804-1811, 2011.

9. J. Li et al., "Homogeneous isolation of nanocellulose from sugarcane bagasse by high pressure homogenization," Carbohydr. Polym., vol. 90, no. 4, pp. 1609-1613, 2012.

10. X. M. Dong, T. Kimura, J.-F. Revol, and D. G. Gray, "Effects of Ionic Strength on the Isotropic-Chiral Nematic Phase Transition of Suspensions of Cellulose Crystallites," Langmuir, vol. 12, no. 8, pp. 2076-2082, 1996.

11. T. Saito et al., "Individualization of nano-sized plant cellulose fibrils by direct surface carboxylation using TEMPO catalyst under neutral conditions," Biomacromolecules, vol. 10, no. 7, pp. 1992-1996, 2009.

12. T. Saito, S. Kimura, Y. Nishiyama, and A. Isogai, "Cellulose nanofibers prepared by TEMPO-mediated oxidation of native cellulose," Biomacromolecules, vol. 8, no. 8, pp. 2485-2491, 2007.

13. J. K. Jackson, K. Letchford, B. Z. Wasserman, L. Ye, W. Y. Hamad, and H. M. Burt, "The use of nanocrystalline cellulose for the binding and controlled release of drugs.," Int. J. Nanomedicine, vol. 6, pp. 321-330, 2011.

14. S. Dong and M. Roman, "Fluorescently labeled cellulose nanocrystals for bioimaging applications," J. Am. Chem. Soc., vol. 129, no. 45, pp. 13810-13811, 2007

15. K. A. Mahmoud, J. A. Mena, K. B. Male, S. Hrapovic, A. Kamen, and J. H. T. Luong, "Effect of surface charge on the cellular uptake and cytotoxicity of fluorescent labeled cellulose nanocrystals," ACS Appl. Mater. Interfaces, vol. 2, no. 10, pp. 2924-2932, 2010.

16. E. Lam, K. B. Male, J. H. Chong, A. C. W. Leung, and J. H. T. Luong, "Applications of functionalized and nanoparticle-modified nanocrystalline cellulose," Trends Biotechnol., vol. 30, no. 5, pp. 283-290, 2012.

17. E. Abraham et al., "Extraction of nanocellulose fibrils from lignocellulosic fibres: A novel approach," Carbohydr. Polym., vol. 86, no. 4, pp. 1468-1475, 2011.

18. I. Y. A. Fatah et al., "Exploration of a chemo-mechanical technique for the isolation of nanofibrillated cellulosic fiber from oil palm empty fruit bunch as a reinforcing agent in composites materials," Polymers (Basel)., vol. 6, no. 10, pp. 2611-2624, 2014.

19. S. Iwamoto, A. N. Nakagaito, and H. Yano, "Nano-fibrillation of pulp fibers for the processing of transparent nanocomposites," Appl. Phys. A Mater. Sci. Process., vol. 89, no. 2, pp. 461-466, 2007.

20. H. P. S. a Khalil, H. Ismail, H. D. Rozman, and M. N. Ahmad, "The effect of acetylation on interfacial shear strength between plant $₫$ bres and various matrices,” Eur. Polym. J., vol. 37, pp. 1037-1045, 2001.

21. N. Sgriccia, M. C. Hawley, and M. Misra, "Characterization of natural fiber surfaces and natural fiber composites," Compos. Part A Appl. Sci. Manuf., vol. 39, no. 10, pp. 1632-1637, 2008.

22. V. Tserki, N. E. Zafeiropoulos, F. Simon, and C. Panayiotou, "A study of the effect of acetylation and propionylation surface treatments on natural fibres," Compos. Part A Appl. Sci. Manuf., vol. 36, no. 8, pp. $1110-1118,2005$.

23. A. Alemdar and M. Sain, "Isolation and characterization of nanofibers from agricultural residues - Wheat straw and soy hulls," Bioresour. Technol., vol. 99, no. 6, pp. 1664-1671, 2008.

24. M. Le Troedec et al., "Influence of various chemical treatments on the composition and structure of hemp fibres," Compos. Part A Appl. Sci. Manuf., vol. 39, no. 3, pp. 514-522, 2008.

25. T. Fisher, M. Hajaligol, B. Waymack, and D. Kellogg, "Pyrolysis behavior and kinetics of biomass derived materials," J. Anal. Appl. Pyrolysis, vol. 62, no. 2, pp. 331-349, 2002.

26. S. M. Mostashari, M. A. Zanjanchi, H. F. Moafi, S. Z. Mostashari, and M. R. B. Chaijan, "Thermogravimetric analysis of a cellulosic fabric incorporated by synthetic ammonium magnesium phosphate as a flame-retardan," Polym. - Plast. Technol. Eng., vol. 47, no. 3, pp. 307-312, 2008.

\section{AUTHORS PROFILE}

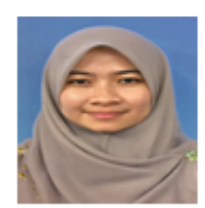

Nurul Husna Osman is a Master Science student from Faculty of Science and Mathematics, Universiti Pendidikan Sultan Idris, Perak, Malaysia. Her area of expertise is in application of nanofibrillated cellulose in packaging materials.

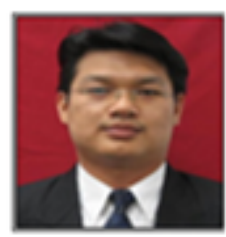

Dr. Rosazley Ramly is a Senior Lecturer in Faculty of Science and Mathematics, Universiti Pendidikan Sultan Idris, Perak, Malaysia majoring in Advanced Material in Pulp and Paper Technology.

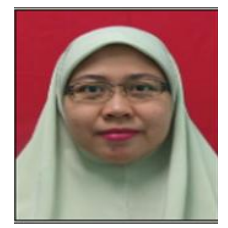

Dr. Wan Haslinda Wan Ahmad is a Senior Lecturer in Faculty of Science and Mathematics, Universiti Pendidikan Sultan Idris, Perak, Malaysia majoring in application of agricultural fibre waste in advanced material.

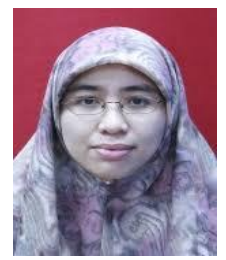

Dr. Ainun Zuriyati Mohamed @ Asa'ari is a Senior Research Officer and Head of Pulp and Paper \& Pollution Control at Laboratory of Biopolymer and Derivatives, Institute of Tropical Forestry and Forest Products (INTROP), Universiti Putra Malaysia, Serdang, Malaysia since 2009. Her area of expertise is in Specialty Paper that applied non-woody as main raw material. 